Indian J. Anim. HIth. (2019), 58(1) : 135-138

DOI: https://doi.org/10.36062/ijah.58.1.2019.135-138

Short Communication

\title{
A CASE STUDY ON ASCITES OF HEPATIC ORIGIN IN A DOG
}

\author{
S. JANA, P. K. DAS, D. BANERJEE, D. GHOSH ${ }^{1}$ \\ P. MUKHERJEE ${ }^{2}$ AND J. MUKHERJEE* \\ Department of Veterinary Physiology \\ West Bengal University of Animal and Fishery Sciences \\ 37, K. B. Sarani, Kolkata-700 037, W.B., India
}

\begin{abstract}
A one and half year old Labrador Retriever bitch was presented to the clinic with the history of anorexia, lethargy and distended abdomen for a month. Upon percussion fluid was evident in the abdomen which was further confirmed through USG. Hematological studies indicated low Hb, PCV and TEC. Blood biochemistry panel showed hypoproteinemia along with elevated SGPT, SGOT and alkaline phosphatase level. ECG showed normal sinus rhythm with low voltage $P$ wave. USG revealed hyperechoic liver tissue along with rounding and irregularity of liver edge suggestive of hepatic abnormalities predisposing to ascites.
\end{abstract}

Key words: Ascites, Dog, Hepatic

Ascites, a common clinical manifestation in dog results from accumulation of fluid in the peritoneal cavity. Accurate treatment of ascites requires proper diagnosis as the underlying cause of ascites can be chronic hepatic failure, congestive heart failure, malnutrition and ancylostomiasis (Randhawa et al., 1988).

A Labrador Retriever bitch aged one and half years was presented as outdoor patient to the clinics, WBUAFS, West Bengal,

*Corresponding author

${ }^{1}$ Department of Veterinary Surgery and Radiology, WBUAFS, Kolkata

${ }^{2}$ Department of VCC, WBUAFS, Mohanpur, Nadia 


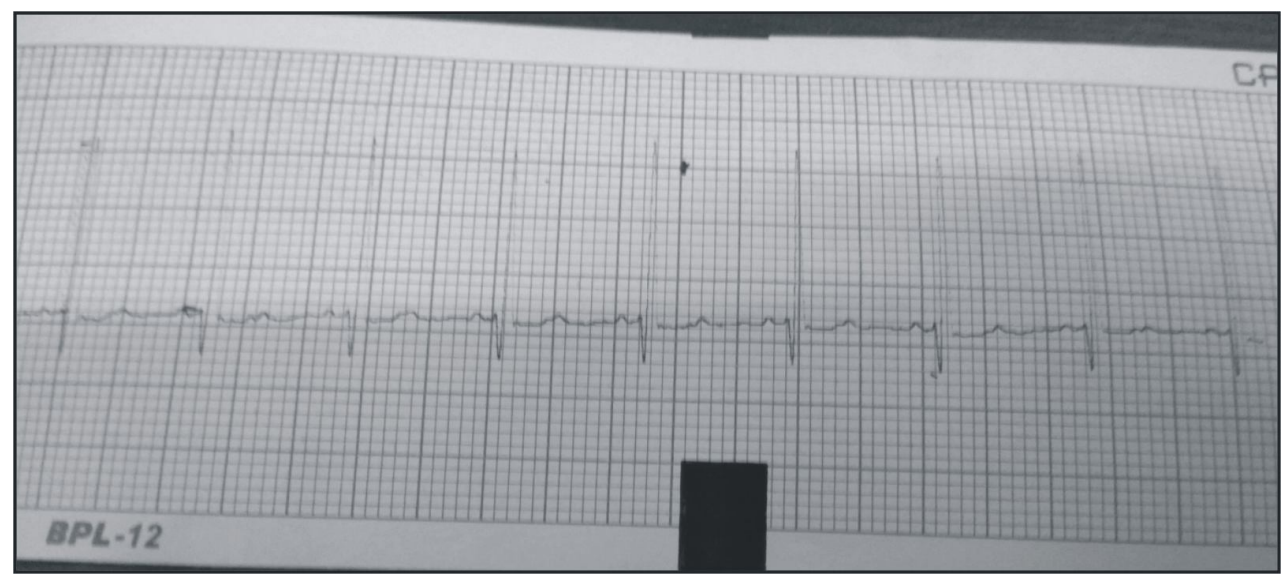

Fig. 1. ECG (Lead-II) showing normal sinus rhythm with low voltage "P" wave

India with the history of distended abdomen, lethargy and anorexia for a week. Clinically the animal was extremely sluggish and weak with distended abdomen. Body temperature was normal $\left(101^{\circ} \mathrm{F}\right)$, but there was marked dyspnoea, pale mucous membrane and the dog fatigued quickly on walking a few steps.

Hematological studies revealed hemoglobin $4.3 \mathrm{gm} \%$, PCV $14 \%$, TEC $2.2 \times 10^{6} / \mathrm{mm}^{3}$, TLC $9600 / \mathrm{mm}^{3}$ and DLC with $61 \%$ neutrophil, $8 \%$ eosinophil, $29 \%$ lymphocyte, $2 \%$ monocyte and platelet count of $220 \times 10^{3} / \mathrm{mm}^{3}$, MCV $63 \mathrm{fl}, \mathrm{MCH}$ $19 \mathrm{pg}$ and MCHC $30 \mathrm{gm} / \mathrm{dL}$. All the erythrocyte indices were within normal range except for hemoglobin, PCV and TEC which were much below the normal range suggesting the animal to be anemic.

Blood biochemical parameters indicated glucose (fasting) $82 \mathrm{mg} / \mathrm{dL}$, urea $11.0 \mathrm{mg} /$ $\mathrm{dL}$, BUN $5.1 \mathrm{mg} / \mathrm{dL}$, creatinine $1.0 \mathrm{mg} / \mathrm{dL}$ and uric acid $0.3 \mathrm{mg} / \mathrm{dL}$. Kidney function tests appeared normal. Total protein was found to be $4.2 \mathrm{gm} / \mathrm{dL}$, albumin $1.3 \mathrm{gm} /$ $\mathrm{dL}$, globulin $2.9 \mathrm{gm} / \mathrm{dL}$, total bilirubin 0.13 $\mathrm{mg} / \mathrm{dL}$, direct bilirubin $0.10 \mathrm{mg} / \mathrm{dL}$, indirect bilirubin $0.03 \mathrm{mg} / \mathrm{dL}$, SGPT $120 \mathrm{IU} / \mathrm{L}$, SGOT 162 IU/L and Alkaline phosphatase ( ALP) 207 IU/L.

The ECG (lead II) was done at the paper speed $25 \mathrm{~mm} / \mathrm{s}$ and sensitivity $10 \mathrm{~mm}=1 \mathrm{mv}$ which showed the heart rate 130 beats per minute with normal sinus rhythm (Fig. 1). However, low voltage ' $\mathrm{P}$ ' waves were found indicating peritoneal effusion.

Upon ultrasonography the presence of anechoic fluid with floating visceral organs were found indicating ascites (Fig. 2). Both the kidneys were found to be normal in 
Indian Journal of Animal Health, June, 2019

\section{Ascites of hepatic origin}

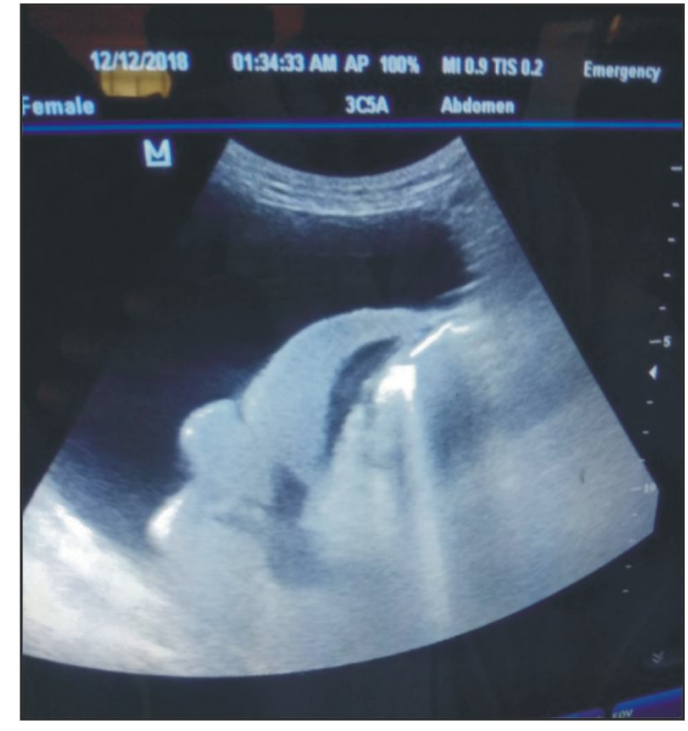

Fig. 2. Sonogram showing accumulation of fluid in abdomen
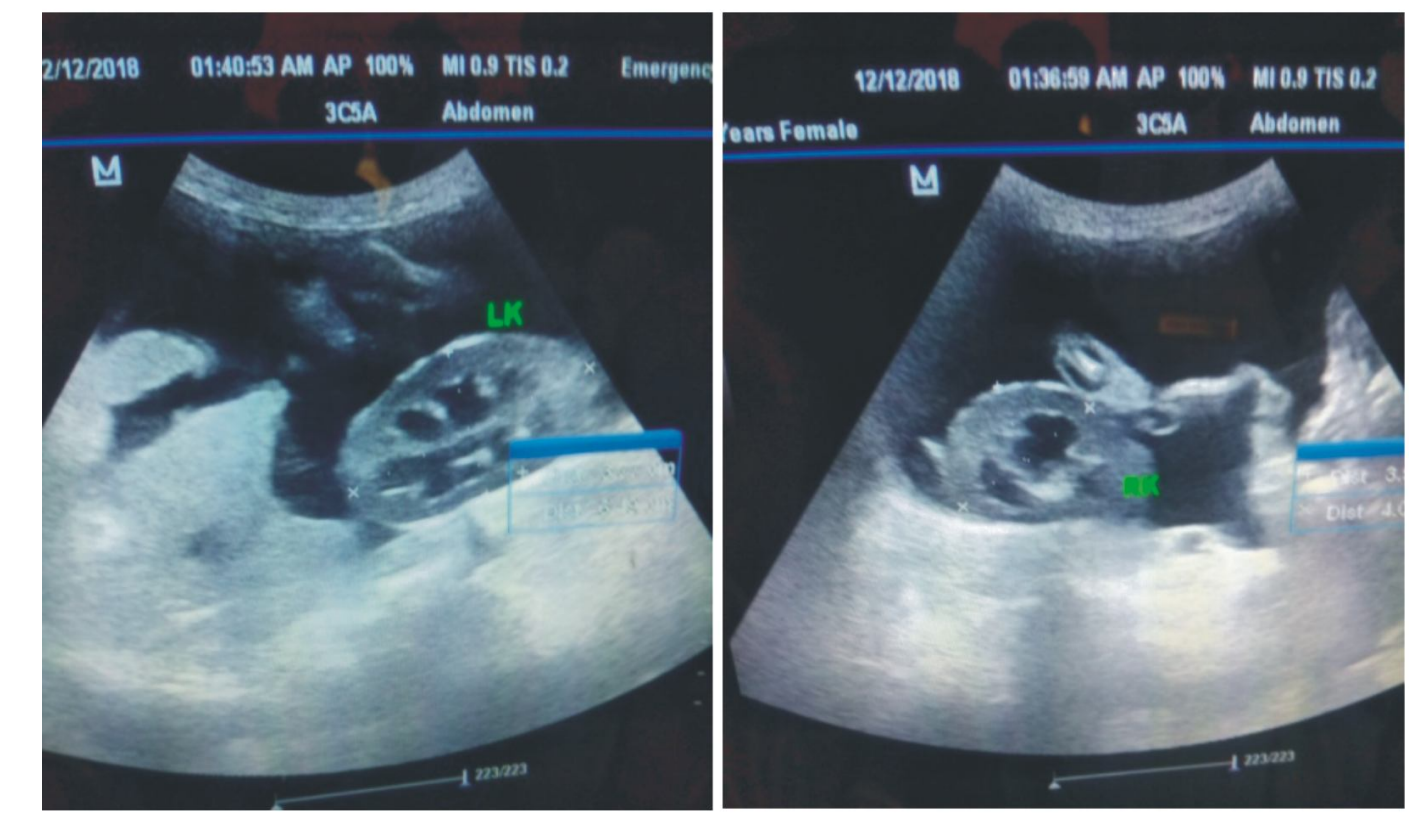

Fig. 3. Sonogram showing left and right kidney

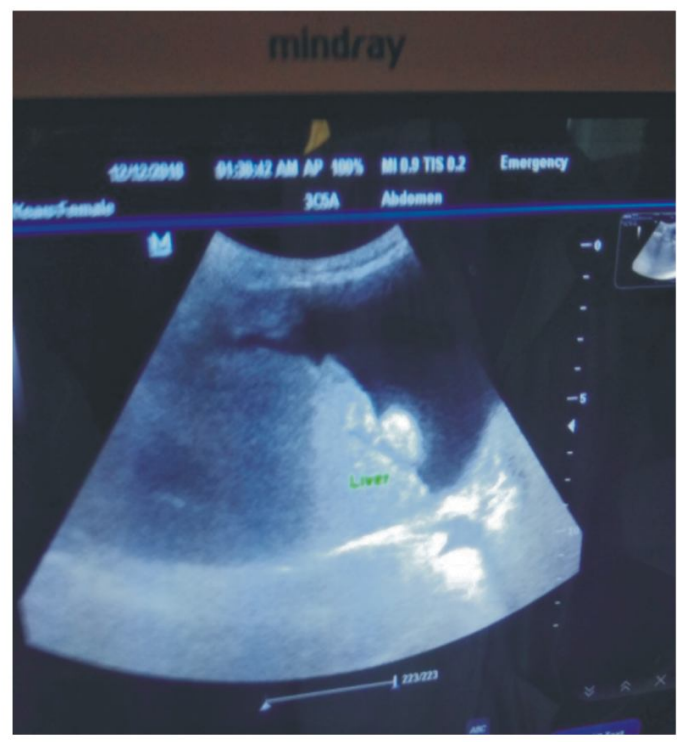

Fig. 4. Sonogram showing liver with increased echogenicity and irregularity in liver edge 
shape and size (left kidney, $6.4 \times 3.77 \mathrm{~cm}$ and right kidney, $4 \times 3 \mathrm{~cm}$ ) with smooth capsule and cortex of uniform ecogenicity (Fig. 3). The USG of liver showed hyperechoic liver tissue along with rounding and irregularity of liver edge (Fig. 4) suggestive of hepatic abnormalities.

The predisposing factors for ascites can be renal (Pradhan et al., 2008), cardiac (Kumar and Srikala, 2014; Mukherjee et al., 2017) and hepatic (Kumar and Srikala, 2014; Sen et al., 2018)

In this present study the renal function appeared normal as indicated by shape and size of kidney along with normal BUN, uric acid and creatinine level. Cardiac involvement can be ruled out as the animal appeared with normal sinus rhythm. Low voltage $\mathrm{P}$ wave may be due to peritoneal fluid accumulation. Decreased level of total protein, albumin as well as increased ALP suggested that ascites may be of hepatic origin which was further strengthened by USG showing irregularity of liver edge and increased echogenicity suggestive of

\section{REFERENCES}

Randhawa SS, Dhaliwal PS, Kirti S and Singh KB, 1988. Ascites of hepatic origin in dogs. Indian J Anim Hlth, 12: $165-166$ hepatitis. The elevated SGOT, SGPT and ALP level also corroborated with the USG findings.

Since hepatic involvement was found in this case, the standard treatment protocol started with antibiotic-ceftriaxone @ 50mg/kg i/v b.i.d for 5 days, diuretic- Furosemide @ 4 $\mathrm{mg} / \mathrm{kg}$ b.i.d orally for 15 days, amino acid and liver tonics along with protein rich but salt free diet. Protein rich food such as egg albumin was suggested. Ursodeoxycholic acid @ 10 mg/kg body weight twice daily for 3 months was advised to be continued as it has protective effect on hepatocellular components and subcellular membranes and also helps in immunomodulations (Meyer $e t$ al., 1997). In this case blood transfusion can also be given as the animal was severely anemic.

Conflict of interests: The authors declare there is no conflict of interests amongst them.

\section{ACKNOWLEDGEMENT}

Authors are extremely grateful to the ViceChancellor, WBUAFS for providing financial support to complete the study.

Pradhan MS, Dakshinkar NP, Waghaye UG and Bodkhe AM, 2008. Successful treatment of ascites of hepatic origin in dog. Vet World, 1(1): 23 
Kumar KS and Srikala D, 2014. Diagnosis and management of cholecystitis in dogs. Int J Agric Sc Vet Med, 2(3): 13-15

Mukherjee P, Mukherjee J, Kesh SS and Das PK, 2017. Ascites of cardiac origin in a dog - a case study. Indian J Anim Hlth, 56(1): 111-112

Sen C, Majie A, Mukherjee J, Ghosh D, Mukherjee $\mathrm{P}$ et al., 2018. Ascites of hepato-cardiac origin in a Labrador retriever dog. Indian J Anim Hlth, 57(1): 99-102

Meyer DJ, Thompson MB and Senior DF, 1997. Use of ursodeoxycholic acids in a dog with chronic hepatitis: Effects on serum hepatic tests and endogenous bile acid composition. J Vet Intern Med, 11: 195-197 